\title{
Healthcare utilisation and costs of home mechanical ventilation
}

\author{
Mika L Nonoyama, ${ }^{1,2}$ Douglas A McKim, ${ }^{3,4}$ Jeremy Road, Denise Guerriere, 5,6,7 \\ Peter C Coyte, ${ }^{6}$ Marina Wasilewski, ${ }^{8}$ Monica Avendano, ${ }^{9,10}$ Sherri L Katz, ${ }^{11,12}$ \\ Reshma Amin, ${ }^{10}$ Roger Goldstein, ${ }^{9,10}$ Brandon Zagorski, ${ }^{6}$ Louise Rose ${ }^{13}$
}

\begin{abstract}
- Additional material is published online only. To view please visit the journal online (http://dx.doi.org/10.1136/ thoraxjn-2017-211138)
\end{abstract}

For numbered affiliations see end of article.

\section{Correspondence to} Dr Mika L Nonoyama, Faculty of Health Sciences, University of Ontario Institute of Technology, Oshawa, ON L1H 7K4, Canada: Mika.Nonoyama@uoit.ca

Received 10 October 2017 Revised 23 November 2017 Accepted 11 December 2017 Published Online First 26 January 2018

\section{Linked}

- http://dx.doi.org/10.1136/ thoraxjnl-2018-211659

Check for updates

To cite: Nonoyama ML, McKim DA, Road J, et al. Thorax 2018;73:644-651.

\section{ABSTRACT}

Background Individuals using home mechanical ventilation (HMV) frequently choose to live at home for quality of life, despite financial burden. Previous studies of healthcare utilisation and costs do not consider public and private expenditures, including caregiver time.

Objectives To determine public and private healthcare utilisation and costs for HMV users living at home in two Canadian provinces, and examine factors associated with higher costs.

Methods Longitudinal, prospective observational cost analysis study (April 2012 to August 2015) collecting data on public and private (out-of-pocket, third-party insurance, caregiving) costs every 2 weeks for 6 months using the Ambulatory and Home Care Record. Functional Independence Measure (FIM) was used at baseline and study completion. Regression models examined variables associated with total monthly costs selected a priori using Andersen and Newman's framework for healthcare utilisation, relevant literature, and clinical expertise. Data are reported in 2015 Canadian dollars ( $\$ C 1=$ US $\$ 0.78=£ 0.51=€ 0.71)$.

Results We enrolled 134 HMV users; 95 with family caregivers. Overall median (IQR) monthly healthcare cost was $\$ 5275$ (\$2291-\$10 181) with $\$ 2410$ (58\%) publicly funded; \$1609 (39\%) family caregiving; and \$141 (3\%) out-of-pocket (<1\% third-party insurance). Median healthcare costs were $\$ 8733$ (\$5868-\$15 274) for those invasively ventilated and $\$ 3925$ (\$1212-\$7390) for noninvasive ventilation. Variables associated with highest monthly costs were amyotrophic lateral sclerosis (1.88, $95 \% \mathrm{Cl} 1.09$ to $3.26, \mathrm{P}<0.03)$ and lower FIM quintiles (higher dependency) (up to $6.98,95 \% \mathrm{Cl} 3.88$ to 12.55 , $\mathrm{P}<0.0001$ ) adjusting for age, sex, tracheostomy and ventilation duration.

Conclusions For HMV users, most healthcare costs were publicly supported or associated with family caregiving. Highest costs were incurred by the most dependent users. Understanding healthcare costs for HMV users will inform policy decisions to optimise resource allocation, helping individuals live at home while minimising caregiver burden.

\section{INTRODUCTION}

Individuals using home mechanical ventilation (HMV) who choose to live at home are a small yet rapidly growing population with prevalence rates ranging from $6.6^{1}$ to $20.0^{2}$ per 100000 adults (12.9/100 000 in Canada). ${ }^{3}$ These individuals have unique and variable healthcare needs requiring a

\section{Key messages}

What is the key question?

- What are the public and private healthcare utilisation and costs for home mechanical ventilation (HMV) and what factors are associated with higher costs?

What is the bottom line?

- For HMV users, most healthcare costs were publicly supported or associated with family caregiving with the highest costs incurred by the most dependent users.

Why read on?

- This prospective study rigorously detailed healthcare costs and confirms the substantial public healthcare cost savings of facilitating mechanical ventilation in the home even when family caregiver time is properly costed, yet indicates that the burden to family caregivers is substantial and needs to be considered in future policy decisions related to HMV.

coordinated strategy for delivery of appropriate and cost-effective care. ${ }^{4}$ Many choose to live at home to promote quality of life, despite the potential physical, psychological and financial burden for themselves and their families. ${ }^{56}$

Current data describing healthcare utilisation and costs for HMV are limited, with few studies considering aspects of both public and private expenditures. $^{78}$ Most studies were published before $2000^{7910}$ and are therefore less valid today. Furthermore, most studies do not provide a monetary value for time devoted to caregiving by family caregivers, or for missed time from employment, or household work for either family caregivers or HMV users. ${ }^{11} 12$ Additional limitations of existing studies include retrospective designs leading to increased risk of recall bias.

Few studies examine factors associated with increased healthcare costs for HMV. In the 1990s, Sevick and Bradham analysed US labour costs of home care services purchased by 277 HMV users and found these increased with older age, greater dependence with activities of daily living and greater technical complexity (medical and equipment) of home care. Labour costs were inversely associated with the number of family caregiving 
hours per day. ${ }^{7}$ Although, this was the largest study of healthcare costs for HMV users to date, it did not consider direct costs associated with emergency department and physician visits, hospitalisations, and ventilator rental and maintenance. ${ }^{7}$

In Canada, few studies describe healthcare utilisation and costs of HMV users, and no study considers both public and private costs. ${ }^{4}{ }^{12}$ Data on HMV user and caregiving factors influencing healthcare utilisation rates and costs are unavailable. These data are essential for informing policy when allocating limited healthcare resources to facilitate optimal support and quality of life for these individuals while minimising caregiver burden. Therefore, our objectives were to determine public and private healthcare utilisation rates and costs for adults using HMV in two Canadian provinces, and to examine factors associated with higher costs.

\section{METHODS}

\section{Design, setting and participants}

We conducted a longitudinal, prospective, observational cost analysis study in two Canadian provinces, Ontario and British Columbia (BC), from April 2012 to July 2014 (Ontario) and June 2014 to August 2015 (BC). In Ontario, the most populous province (approximately 13 million), public and private healthcare services for HMV users vary across 14 different health networks. ${ }^{3}$ Ontario has a ventilator equipment pool (VEP), which provides publicly funded mechanical ventilators, related equipment and supplies. In BC (estimated population 5 million), a province-wide and publicly funded HMV programme supports adult HMV users with ventilators and equipment and also respiratory care services and education in the home. Each province is responsible for the administration and delivery of services under federal government regulation. ${ }^{13}$

In Ontario, we recruited participants using convenience sampling from the VEP and West Park Healthcare Centre's LongTerm Ventilation Centre of Excellence. In BC, we recruited from the BC Association for Individualized Technology and Supports for People with Disabilities, Provincial Respiratory Outreach Program (PROP). Three participants transitioning to adult care (18 years old) were recruited from the Children's Hospital of Eastern Ontario (CHEO). At the time of the study, the sampling frame was approximately 1100 (700 from VEP/West Park/ CHEO and 400 from PROP). Potential study participants were identified by the organisation's staff and mailed or handed a recruitment letter. Participants who were interested in obtaining more information or taking part in the study were contacted by study investigators.

Inclusion criteria for HMV users were: $\geq 18$ years old; invasive or non-invasive bilevel (pressure or volume) mechanical ventilation for $\geq 6$ hours a day; and living in a private dwelling (including attendant care apartments) for at least 6 months after transition. We selected this time frame as we were interested in relatively stable home care costs as opposed to those incurred during transition. Both HMV user/caregiver dyads and individuals without a family caregiver were included. HMV users were interviewed directly unless they were unable to communicate. Inclusion criteria for caregivers were: $\geq 18$ years old; and family member or friend most responsible for providing and/or coordinating care without financial compensation. Exclusion criteria were: using only CPAP and unable to read/speak English/French. Written and informed consent was obtained from all study participants.

\section{Measures}

We collected demographic data including age, sex, living arrangement, marital status, highest education level, employment status, diagnosis requiring ventilation, date initiated, ventilation interface (eg, tracheostomy, mask), ventilation hours per day, number of ventilators and household income. We documented chronic conditions using the Canadian Community Health Survey's Chronic Conditions module ${ }^{14}$ and measured functional status using the Functional Independence Measure (FIM) ${ }^{15}$ at study enrolment and at 6 months. The FIM measures disability based on burden of caring, with 13 motor and 5 cognition domains. It has been validated and standardised in individuals with spinal cord injury, traumatic brain injury and multiple sclerosis. ${ }^{15} \mathrm{~A}$ higher FIM score (scale 18-126) represents more independent function. Caregiver demographic information included age, sex, relationship to HMV user, marital status, highest education level and employment status.

To minimise recall bias, we collected cost and utilisation data every 2 weeks for 6 months using the Ambulatory and Home Care Record (AHCR) ${ }^{16}$ by telephone interview. The AHCR assesses both public and private healthcare expenditures and has been reliably used in various populations ${ }^{17}$ including palliative care $^{18}$ and people living with chronic conditions. ${ }^{19}$ Data collected comprised all costs covered by the public sector including ambulatory/outpatient, inpatient and home-based health services. In Canada, most (approximately 70\%) medically necessary health services are publicly insured, exceptions include some medications, vision care, dental care and allied health services. We collected data on health services covered by the private sector including third-party insurance and out-of-pocket spending, caregiving costs (time) incurred by family caregivers and costs to employers due to caregiver or HMV user absenteeism.

\section{Calculation of costs}

We used established methods for generating costs. ${ }^{1620}$ We aggregated all costs over the 6 months and reported median (IQR) monthly costs (rate per 30 days) in 2015 Canadian dollars (\$C). We grouped costs into three categories: publicly funded health services; privately funded health services; and time costs incurred by family caregivers. Categories considered costs associated with personnel, equipment, supplies and medications (see online supplementary material).

We obtained physician and laboratory costs from the Ontario Health Insurance Schedule of Benefits, Schedule of Benefits for Laboratory Services (Ontario) and the Medical Services Plan (BC). We obtained medication costs from the government-sponsored Ontario Drug Benefit (ODB) programme, PharmaCare (BC) and RxTx (formerly eCPS and eTherapeutics). Payment rates from public home care agencies were used to calculate costs associated with home care personnel. Disposable supply costs were derived from the Ontario Assistive Devices Program product manuals, BC Ministry of Health's payment schedules, a publicly funded homecare agency, PROP's suggested yearly inventory and a previous study. ${ }^{18}$

Unpaid caregiver time costs were calculated using the human capital approach. $^{21} 22$ We applied 2011 Canadian census age/ sex-based earnings estimates, adjusted for $15 \%$ nominal earnings growth to 2015 , multiplied by 1.20 for employer paid benefits, and further multiplied by $52 / 46$ to account for vacation days and holidays. Time lost from household work/leisure was calculated using the 2011 Canadian census estimated earnings of a homemaker and adjusted for earnings growth, fringe benefits, vacation days and holidays. For each participant, the total time 
cost was the product between the monetary value of one unit of time and the total time of caregiving. ${ }^{16}$

\section{Sample size}

Based on recommendations for fitting multivariable models, a minimum of $50+8 \mathrm{~m}$ (where $\mathrm{m}$ is the number of predictors) study participants is required to avoid overfitting. ${ }^{23}$ Therefore, a minimum sample of 122 participants was required to assess the association of nine independent variables with 30-day total costs (dependent variable).

\section{Data analysis}

We used descriptive statistics to describe healthcare utilisation for the overall study cohort, according to duration of ventilation duration per day, ventilatory interface (invasive or non-invasive), disease and province. Because the different cost categories did not sum to the total statistically derived median cost, the proportion of each category was calculated using the sum of median public+caregiver lost time+ private out-of-pocket + third-party insurance as the denominator. A priori variables considered associated with increased healthcare costs were selected using Andersen and Newman's ${ }^{24}$ framework for healthcare utilisation, relevant literature and clinical expertise. We generated a multivariate linear regression model of monthly total costs with age, sex, functional status (quartiles of FIM total score, the lowest of the two baseline and study completion scores), ventilation status (invasive vs non-invasive); maximal daily ventilation duration (hours/day), diagnosis (amyotrophic lateral sclerosis (ALS), COPD, muscular dystrophies, other) and province (Ontario, BC) as independent variables. Exponentiated estimates and their 95\% CIs were determined. As participants provided data at multiple time points, we controlled for within-person correlation using a first-order autoregressive covariance structure.

\section{RESULTS \\ Demographics}

Between April 2012 to July 2014 (Ontario) and June 2014 to August 2015 (BC), $134 \mathrm{HMV}$ users (86 Ontario, 53 BC) were enrolled. Ninety-five (71\%) (68 Ontario, 27 BC) were identified as family caregivers, 69 living with them. Mean (SD) age was 56.5 (17.2) years, 76 (57\%) were male; 45 (34\%) were invasively ventilated via tracheostomy. Participants required HMV for a median (IQR) of $8.0(2.5-15.2)$ years and now required $10.0(8.0-24.0)$ hours on average per day (table 1$)$. The median (IQR) total, cognitive and motor FIM scores at baseline were 88.1 (51.5-115.3), $33.5(32.0-34.0)$ and 56.5 (18.0-82.0), respectively. Scores were lowest across all domains for individuals with ALS $(n=17)$ of 49.3 (44.5-72.9), 33.0 (31.0-34.0) and 18.5 (13.0-38.9). Mean (SD) age of primary caregivers was 60 (11) years; $72(76 \%)$ were female (table 1$)$.

\section{Monthly healthcare costs}

The overall median (IQR) monthly healthcare cost per individual was \$5275 (\$2291-\$10181). Over half (58\%, \$2410, \$955-\$361) of the overall monthly healthcare costs were publicly funded; 39\% (\$1609, \$0-\$5527) were family caregiver time costs; 3\% (\$141, \$67-\$438) out-of-pocket costs; and less than $1 \%(\$ 0, \$ 0-\$ 21)$ third-party insurance (table 2).

Median (IQR) cost for non-invasively ventilated individuals was \$3925 (\$1212-\$7390); \$8733 (\$5868-\$15274) for those invasively ventilated. The per cent breakdown of publicly funded, caregiver time costs, out-of-pocket costs and third-party insurance was similar to the overall cohort (table 2). With respect to daily duration of ventilation, the highest median (IQR) monthly cost was incurred by individuals ventilated more than 20 hours/ day $(n=41)$ at $\$ 8551(\$ 6131-\$ 17090)$ (table 2$)$. When examining costs associated with diagnosis, ALS incurred the highest costs at \$12876 (\$8495-\$17565), followed by Duchenne muscular dystrophy (DMD) at \$8419 (\$5868-\$10297) and other muscular dystrophies at \$8197 (\$3942-\$13 970) (table 3). We identified large provincial differences in the proportion of costs assigned to different cost categories with HMV users in BC using more publicly funded healthcare at 98\% (\$4000 (\$1546$\$ 5983))$ vs 39\% (\$1500 (\$629-\$4516)) in Ontario. Caregiving time costs were $0 \%(\$ 0(\$ 0-\$ 4950))$ in BC vs $56 \%(\$ 2141$ (\$62-\$6262)) in Ontario (online supplementary tables S1 and S2). For most of the HMV user dyads, there was an inverse cost relationship of public healthcare utilisation and caregiver lost time, for example, for individuals with DMD, $98 \%$ of costs were publicly incurred and $0 \%$ were associated with caregiving; for those with kyphoscoliosis, $27 \%$ of costs were publicly incurred and $64 \%$ were related to caregiving (figure 1).

In our multivariable model, variables associated with the highest monthly costs included ALS (estimate 1.88, 95\% CI 1.09 to $3.26, \mathrm{P}=0.03$ ) representing an $88 \%$ increase in median monthly cost compared with those with COPD, and the three lower FIM score quintiles (lowest quintile estimate 6.98, 95\% CI 3.88 to $12.55, \mathrm{P}<0.001$ ) representing a $300 \%-700 \%$ increase in median costs compared with the highest functioning group (highest quartile). This model adjusted for sex, age, invasive/ non-invasive ventilation and duration of daily ventilation, and explained $55 \%$ of the variation in total monthly cost (table 4).

\section{DISCUSSION}

To our knowledge, this study is the first to provide a comprehensive description of public and private healthcare costs of HMV including costs associated with caregiving. Median monthly healthcare cost (2015 \$C) per individual was \$5275 with 58\% derived from public funding and 39\% associated with family caregiving time costs. Multivariable modelling demonstrated that highest monthly healthcare costs were associated with ALS and the lower levels of functional independence. Although we found higher costs for invasive ventilation compared with non-invasive ventilation and increasing hours of daily mechanical ventilation, these were not associated with higher costs in this model.

The monthly median cost of $\$ 5275$ for our cohort is equivalent to $\$ 63300$ each year; considering the most costly group, ALS, the median annual cost is estimated at $\$ 154512$. Previous Canadian reports estimate the per diem costs of individuals requiring ventilation and cared for in an intensive care unit would range from $\$ 2328$ to $\$ 4435$ (\$849720-\$1 618775 per year) with costs of \$921-\$1587 (\$336165-\$579 255) (2015 \$C) in a chronic respiratory, weaning, step-down or rehabilitation unit. ${ }^{25}$ We found an inverse relationship in costs associated with public healthcare utilisation and costs incurred through family caregiving, that is, in Ontario HMV users accessed more publicly funded healthcare services (39\%) and less family caregiving (56\%). Conversely in BC, which has a province-wide and publicly funded HMV programme that includes access to personnel as well as equipment, public healthcare costs comprised 98\% whereas caregiver costs were $0 \%$ of total median costs. Although this is a Canadian example, it illustrates investing more in healthcare policy for provision of healthcare services that enable more HMV users to live and stay at home while providing appropriate levels of support to family caregivers may be a wise public healthcare investment that may result in substantial cost savings, when 
Table 1 Demographic characteristics of HMV users and caregivers

\begin{tabular}{|c|c|c|c|}
\hline HMV user $(n=134)$ & n (\%), unless specified & Caregiver $(n=95)$ & n (\%), unless specified \\
\hline Age (mean (SD)), years & $56.5(17.2)$ & Age (mean (SD)), years & $60.0(11.1)$ \\
\hline Male & $73(56.7)$ & Female & $72(75.8)$ \\
\hline Diagnosis & & Marital status & \\
\hline COPD or other chronic lung disease & $21(15.7)$ & Married & $75(78.9)$ \\
\hline Amyotrophic lateral sclerosis & $17(12.7)$ & Never married & $4(4.2)$ \\
\hline DMD & $9(6.7)$ & Divorced/separated & $5(5.3)$ \\
\hline Muscular dystrophies other than DMD & $14(10.4)$ & Widowed & $3(3.2)$ \\
\hline Postpolio syndrome & $11(8.2)$ & Missing & $8(8.4)$ \\
\hline Spinal cord injury & $14(10.4)$ & Education level ( $n=11$ missing) & \\
\hline Central hypoventilation syndrome & $5(3.7)$ & High school or less & $24(25.3)$ \\
\hline Sleep apnoea & $3(2.2)$ & Any vocation/college & $33(34.7)$ \\
\hline Diaphragmatic paralysis & $2(1.5)$ & Any university & $23(24.2)$ \\
\hline Kyphoscoliosis/scoliosis & $4(3.0)$ & Postgraduate & $4(4.2)$ \\
\hline Other*, unknown or missing & $34(25.3)$ & Employment status ( $\mathrm{n}=9$ missing) & \\
\hline Ventilation interface & & Retired & $38(40.0)$ \\
\hline Tracheostomy & $45(33.6)$ & Full-time & $19(20.0)$ \\
\hline Mask (face, nasal) & $68(50.8)$ & Not employed & $15(15.8)$ \\
\hline Mouthpiece, diaphragmatic pacer & $4(2.9)$ & Part-time/casual & $7(7.4)$ \\
\hline Multiple interfaces & $17(12.7)$ & Student, disability, on leave, self-employed & $7(7.4)$ \\
\hline Duration of HMV, years (median (IQR)) & $8.0(2.5-15.2)$ & Relationship to HMV user & \\
\hline Daily duration of HMV, hours/day (median (IQR)) & $10.0(8.0-24.0)$ & Wife & $38(40.0)$ \\
\hline Living arrangement & & Parent & $23(24.2)$ \\
\hline With spouse & $60(44.8)$ & Husband & $13(13.7)$ \\
\hline Alone & $43(32.1)$ & Daughter/daughter-in-law, son & $9(9.5)$ \\
\hline With parents & $21(15.7)$ & Extended family, friend/neighbour & $12(12.6)$ \\
\hline With friends, children or others & $10(7.4)$ & & \\
\hline \multicolumn{4}{|l|}{ Marital status } \\
\hline Married & $61(45.5)$ & & \\
\hline Never married & $49(36.6)$ & & \\
\hline Divorced/separated & $8(6.0)$ & & \\
\hline Widow & $16(11.9)$ & & \\
\hline \multicolumn{4}{|l|}{ Education level } \\
\hline High school or less & $44(32.8)$ & & \\
\hline Any vocational/college & $38(28.4)$ & & \\
\hline Any university & $39(29.1)$ & & \\
\hline Postgraduate & $13(9.7)$ & & \\
\hline Number of chronic conditions (median (IQR)) & $4.0(2.0-6.0)$ & & \\
\hline \multicolumn{4}{|l|}{ Household income } \\
\hline$\leq \$ 25000$ & $28(20.9)$ & & \\
\hline$\$ 25001-\$ 45000$ & $29(21.6)$ & & \\
\hline$\$ 45001-\$ 65000$ & $18(13.4)$ & & \\
\hline$\geq \$ 65001$ & $29(21.6)$ & & \\
\hline Don't know/refused & $30(22.3)$ & & \\
\hline
\end{tabular}

compared with institutionalisation. Such an investment should include infrastructure such a centralised HMV programme providing equipment that includes access to respiratory specialists in the home and appropriate levels of support for publicly funded caregivers as well as caregiver respite, education, training programmes and day-to-day assistance. ${ }^{2627}$ The 
Table 2 Monthly healthcare costs for the entire cohort by daily duration of ventilation and by ventilator interface

\begin{tabular}{|c|c|c|c|c|c|c|}
\hline \multirow[b]{2}{*}{ Item } & $\begin{array}{l}\text { Entire cohort } \\
(n=134)\end{array}$ & $\begin{array}{l}\text { Non-invasive } \\
(\mathrm{n}=89)\end{array}$ & $\begin{array}{l}\text { Invasive } \\
(\mathrm{n}=45)\end{array}$ & $\begin{array}{l}<10 \text { hours } \\
(n=54)\end{array}$ & $\begin{array}{l}10-19 \text { hours } \\
(n=39)\end{array}$ & \multirow[t]{2}{*}{$\begin{array}{l}\geq 20 \text { hours } \\
(n=41)\end{array}$} \\
\hline & \multicolumn{5}{|c|}{ Median (IQR), \% of total summed cost* } & \\
\hline Total public & $\begin{array}{l}2410 \\
(955-5361) 58 \%\end{array}$ & $\begin{array}{l}1380 \\
(572-3440) 53 \%\end{array}$ & $\begin{array}{l}5246 \\
(2730-7333) 54 \%\end{array}$ & $\begin{array}{l}1222 \\
(423-3970) 76 \%\end{array}$ & $\begin{array}{l}1542 \\
(762-3228) 39 \%\end{array}$ & $\begin{array}{l}5800 \\
(4000-8021) 62 \%\end{array}$ \\
\hline Home-based visits & $622(27-3723)$ & $101(15-1002)$ & $3780(2036-5106)$ & $62(12-692)$ & $162(25-2109)$ & $3825(2346-5634)$ \\
\hline Ambulatory-based clinic visits & $144(73-249)$ & $153(85-252)$ & $106(69-189)$ & $183(86-284)$ & $153(99-200)$ & $91(13-173)$ \\
\hline Hospitalisation ED hospice care & $0(0-1002)$ & $0(0-288)$ & $37(0-1092)$ & $0(0-648)$ & $0(0-288)$ & $0(0-1098)$ \\
\hline Medications & $175(65-392)$ & $173(36-344)$ & $184(123-487)$ & $159(46-303)$ & $158(40-392)$ & $240(147-507)$ \\
\hline Supplies & $173(38-410)$ & 68 (9-408) & $244(157-410)$ & $52(1-249)$ & $203(50-473)$ & $280(165-574)$ \\
\hline Caregiver lost time & $\begin{array}{l}1609 \\
(0-5527) 39 \%\end{array}$ & $\begin{array}{l}1108 \\
(0-3559) 42 \%\end{array}$ & $\begin{array}{l}4262 \\
(0-6586) 44 \%\end{array}$ & $\begin{array}{l}236 \\
(0-2547) 15 \%\end{array}$ & $\begin{array}{l}2257 \\
(126-6880) 58 \%\end{array}$ & $\begin{array}{l}3380 \\
(0-6262) 36 \%\end{array}$ \\
\hline Total private out-of-pocket & $\begin{array}{l}141 \\
(67-438) 3 \%\end{array}$ & $\begin{array}{l}136 \\
(73-438) 5 \%\end{array}$ & $\begin{array}{l}142 \\
(67-403) 1 \%\end{array}$ & $\begin{array}{l}151 \\
(73-365) 9 \%\end{array}$ & $\begin{array}{l}125 \\
(63-403) 3 \%\end{array}$ & $\begin{array}{l}148 \\
(78-502) 2 \%\end{array}$ \\
\hline HCP visits (in or out of home) & $17(0-92)$ & $30(0-79)$ & $0(0-98)$ & $19(0-58)$ & $17(0-97)$ & $8(0-159)$ \\
\hline Travel & $30(13-81)$ & $45(18-85)$ & $26(10-55)$ & $44(15-97)$ & $45(18-82)$ & $27(10-45)$ \\
\hline Medications & $4(0-18)$ & $3(0-15)$ & $13(0-28)$ & $9(1-18)$ & $1(0-16)$ & $9(0-25)$ \\
\hline Supplies & $30(4-149)$ & $24(3-134)$ & $51(6-178)$ & $20(2-104)$ & $27(8-131)$ & $69(5-264)$ \\
\hline Total third-party insurance & $0(0-21) 0 \%$ & 0 (0-29) $0 \%$ & $0(0-7) 0 \%$ & $0(0-33) 0 \%$ & $0(0-37) 0 \%$ & 0 (0-6) $0 \%$ \\
\hline Home-based visits & 0 & 0 & 0 & 0 & $0(0-5)$ & 0 \\
\hline Medications & 0 & 0 & 0 & 0 & 0 & 0 \\
\hline Supplies & 0 & 0 & 0 & 0 & 0 & 0 \\
\hline Total healthcare costs & $\begin{array}{l}5275 \\
(2291-10181)\end{array}$ & $\begin{array}{l}3925 \\
(1212-7390)\end{array}$ & $\begin{array}{l}8733 \\
(5868-15274)\end{array}$ & $\begin{array}{l}2997 \\
(950-5304)\end{array}$ & $\begin{array}{l}4980 \\
(2291-10181)\end{array}$ & $\begin{array}{l}8551 \\
(6131-17090)\end{array}$ \\
\hline
\end{tabular}

Monthly healthcare costs for HMV users in the entire cohort, those ventilated $<10,10-19$ and $\geq 20$ hours/day, and those ventilated non-invasively or invasively in $2015 \$ C$.

*Because different cost categories did not sum to the total statistically derived median cost, the proportion of each category was calculated using the sum of median public+caregiver lost time+private out-of-pocket+third-party insurance as the denominator.

ED, emergency department; HCP, healthcare provider; HMV, home mechanical ventilation.

median monthly healthcare costs we report differ substantially from those in other studies; however, comparison is problematic due to differences in study methods as well as differences in funding mechanisms and patterns of healthcare provision. In the US cross-sectional survey, we highlight in our introduction ${ }^{7}$ the total labour median monthly cost of HMV home care (private and public) was \$8201 (1995 US\$) (\$16 234 (2015 \$C)). This is greater than costs incurred by the most dependent patients in our study and likely represents differences in healthcare funding and provision between the USA and Canada. Another reason for disparate findings may be differences in our HMV cohort. Thirty-four per cent of our cohort required tracheostomy ventilation with a median monthly healthcare cost of $\$ 8733$ compared with $\$ 3925$ for those on non-invasive ventilation. Previous studies have included a higher proportion of individuals on tracheostomy ventilation. ${ }^{712}$ Klein and Forshew similarly reported much lower costs for non-invasive ventilation at \$435 (1996 US\$) per month (\$825 (2015 \$C)) compared with \$16 625 (1996 US\$) for tracheostomy ventilation (\$32 260 (2015 \$C)) for individuals with ALS, though this difference is markedly greater than found in our cohort. ${ }^{28}$ Another reason for the disparity in costs compared with those reported in previous studies is that our cohort is well established using ventilation at home, on average 10 years. Therefore, our data are representative of stable costs of HMV as they exclude those incurred during the highly expensive transition to home period. These costs that include items such as home renovation, new equipment and caregiver training have been shown to be much higher, especially if ventilation is commenced in the hospital. ${ }^{122930}$ As an example, a previous
Canadian report ${ }^{12}$ describing only healthcare personnel costs during transition to home, found that the mean monthly cost was $\$ 11093$ (2015 \$C).

We found that the highest monthly healthcare costs were associated with ALS and low levels of functional ability. Previous studies support this finding. ${ }^{7}$ In a review of 12 studies describing costs associated with ALS (some were HMV users), Gladman and Zinman identified drivers of cost included more severe disease, lower levels of functional ability defined as increased support with activities of daily living and mechanical ventilation. ${ }^{31}$ Similarly, studies with HMV users with $\mathrm{ALS}^{32}$ and mixed diagnoses ${ }^{10}$ indicate that increased healthcare costs were incurred by individuals with more complex health needs and higher functional dependency defined as the need for skilled healthcare personnel, respiratory equipment and supplies.

We found that $39 \%$ of monthly healthcare cost was incurred through family caregiver time. As noted earlier, few studies have considered family caregiving when calculating the cost of HMV; the 13 studies we found had highly variable costs due to different calculation methods. Sevick and Bradham ${ }^{7}$ reported that median cost of home care rose by 41\% (\$2006-\$3409 (1995 US\$); \$4564 (2015 \$C)) when family caregiving time was considered, using opportunity costing methods (market-based earning capacity of the caregiver based on education and skill). ${ }^{7}$ Overall caregiving costs were higher compared with our cohort but were similar for those receiving tracheostomy ventilation or ventilated $>20$ hours/day. Variability in caregiving time cost reporting may also be due to cohort characteristics. Two studies, one with an international DMD cohort, the other a Spanish ALS 
Table 3 Monthly healthcare costs for HMV users by diagnosis

\begin{tabular}{|c|c|c|c|c|c|}
\hline Diagnosis & Total public & Caregiver lost time & $\begin{array}{l}\text { Total private out-of- } \\
\text { pocket }\end{array}$ & $\begin{array}{l}\text { Total third-party } \\
\text { insurance }\end{array}$ & Total healthcare costs \\
\hline \multirow[t]{2}{*}{ Amyotrophic lateral sclerosis $(n=17)$} & $5042(2040-7903)$ & $5890(3805-6997)$ & $656(178-1987)$ & $0(0-99)$ & $12876(8495-17565)$ \\
\hline & $44 \%$ & $51 \%$ & $6 \%$ & $0 \%$ & \\
\hline \multirow[t]{2}{*}{$\operatorname{DMD}(n=9)$} & $5394(4432-8021)$ & $0(0-5907)$ & $46(20-187)$ & $0(0-10)$ & 8419 (5868-10 297) \\
\hline & $99 \%$ & $0 \%$ & $1 \%$ & $0 \%$ & \\
\hline Other muscular dystrophies $(n=14)$ & 4040 (2494-8334) & $1425(0-4950)$ & $103(25-208)$ & $1(0-13)$ & 8197 (3942-13 970) \\
\hline \multirow[t]{2}{*}{ Spinal cord injury $(n=14)$} & $4869(4000-6396)$ & $0(0-8096)$ & $372(63-719)$ & $0(0-7)$ & $6093(5190-13473)$ \\
\hline & $93 \%$ & $0 \%$ & $7 \%$ & $0 \%$ & \\
\hline \multirow[t]{2}{*}{ Chronic lung disease $(n=21)$} & $1380(965-2664)$ & $2003(1108-2984)$ & $116(79-219)$ & $0(0-33)$ & 3554 (2291-4980) \\
\hline & $39 \%$ & $57 \%$ & $3 \%$ & $0 \%$ & \\
\hline Postpolio syndrome $(n=11)$ & 651 (157-1587) & $0(0-95)$ & $86(41-196)$ & $0(0-19)$ & 735 (265-2283) \\
\hline \multirow[t]{2}{*}{ Kyphoscoliosis/scoliosis $(n=4)$} & $627(502-832)$ & $1503(149-3065)$ & $196(84-316)$ & $34(10-51)$ & 2571 (1117-3892) \\
\hline & $27 \%$ & $64 \%$ & $8 \%$ & $1 \%$ & \\
\hline \multirow[t]{2}{*}{ Sleep apnoea $(n=3)$} & $572(103-1083)$ & $0(0-60)$ & $60(18-91)$ & $0(0-38)$ & $591(224-1212)$ \\
\hline & $91 \%$ & $0 \%$ & $9 \%$ & $0 \%$ & \\
\hline \multirow[t]{2}{*}{ Diaphragmatic paralysis $(n=2)$} & $376(227-525)$ & $815(9-1621)$ & $167(120-213)$ & $8(0-16)$ & $1366(356-2375)$ \\
\hline & $28 \%$ & $60 \%$ & $12 \%$ & $1 \%$ & \\
\hline \multirow[t]{2}{*}{ Other* $(n=34)$} & $1465(423-4469)$ & $2137(62-5527)$ & $139(84-365)$ & $0(0-23)$ & $5968(1436-8802)$ \\
\hline & $90 \%$ & $9 \%$ & $1 \%$ & $0 \%$ & \\
\hline
\end{tabular}

Median and IQR (upper numbers) and per cent of total (lower numbers) of monthly healthcare costs for HMV users by diagnosis in 2015 \$C.

* Other diagnoses: see table 1. Because different cost categories did not sum to the total statistically derived median cost, the proportion of each category was calculated using the sum of median public+caregiver lost time+private out-of-pocket+third-party insurance as the denominator.

DMD, Duchenne muscular dystrophy; HMV, home mechanical ventilation.

cohort (not all of whom received mechanical ventilation in the home), report costs attributable to family caregiver time represented 18\%-31\% annual costs for $\mathrm{DMD}^{33}$ (mean \$13370-\$18 530 (2012 US\$); \$13977-\$19 371 (2015 \$C)) and 53\% of costs for $\mathrm{ALS}^{34}$ (mean €19 125 (2004); \$14 381 (2015 \$C)). In our cohort, caregiving time costs for DMD were much lower $(0 \%$ of total median cost, median (IQR) \$0 (0-5907)), though we only recruited nine individuals with this diagnosis (moderate function with a mean total FIM score 55 out of 126). Caregiving time cost for our HMV cohort with ALS was 51\% of monthly costs, which is comparable to those of the Spanish cohort.

Our study provides detailed information on the public and private healthcare costs of HMV which can inform policymaking decisions on funding allocation. For instance, those individuals with higher functional dependence and/or a diagnosis of ALS may warrant more publicly funded support. Additionally, costs associated with family caregiver time were equivalent to $39 \%$ of all healthcare costs and therefore highlight the reliance of the current public healthcare funding model on provision of care by family caregivers. However, this reliance is likely to result in physical, psychological and financial burden on caregivers. Liu and colleagues ${ }^{6}$ found greater physiological and social burden for family caregivers of HMV users living at home in Taiwan compared with caregivers of those living in a chronic respiratory care ward. Current financial supports for family caregivers including tax credits, ${ }^{35}$ employment insurance benefits, ${ }^{35} 36$ home modification and vehicle modification programmes, ${ }^{37} 38$ and paid leaves for family caregiving ${ }^{39}$ in Canada are limited.
However, many HMV users live years at home and require daily care, requiring the presence of family caregivers for much more extended time periods.

\section{Strengths and limitations}

Irrespective of differences in study design and country of origin, our study offers a comprehensive estimate of HMV home healthcare costs considering both publicly and privately funded health services, and time costs incurred by family caregivers as well as prospectively measuring costs every 2 weeks using a well-established and validated tool over 6 months to minimise recall bias. However, our study has limitations. First, despite collecting healthcare utilisation data every 2 weeks using a validated tool, our data may be subject to recall bias. Second, participants may have provided data that fit with perceived social norms, for example, overestimating or underestimating the time provided for family caring (social desirability bias). ${ }^{40}$ Third, our costing estimates may not be completely accurate as participants did not always know the costs of items, especially those paid out-ofpocket or by third-party insurance, despite our best efforts to locate all costs. Additionally, third-party insurance costs may have been underestimated because the majority of participants may not have possessed it (we did not collect these data). Fourth, study sample characteristics may differ from the broader Canadian HMV user population ${ }^{3}$ as invasive HMV users are over-represented, and under-representing HMV users with ALS, central hypoventilation syndrome, muscular dystrophies and chest wall 


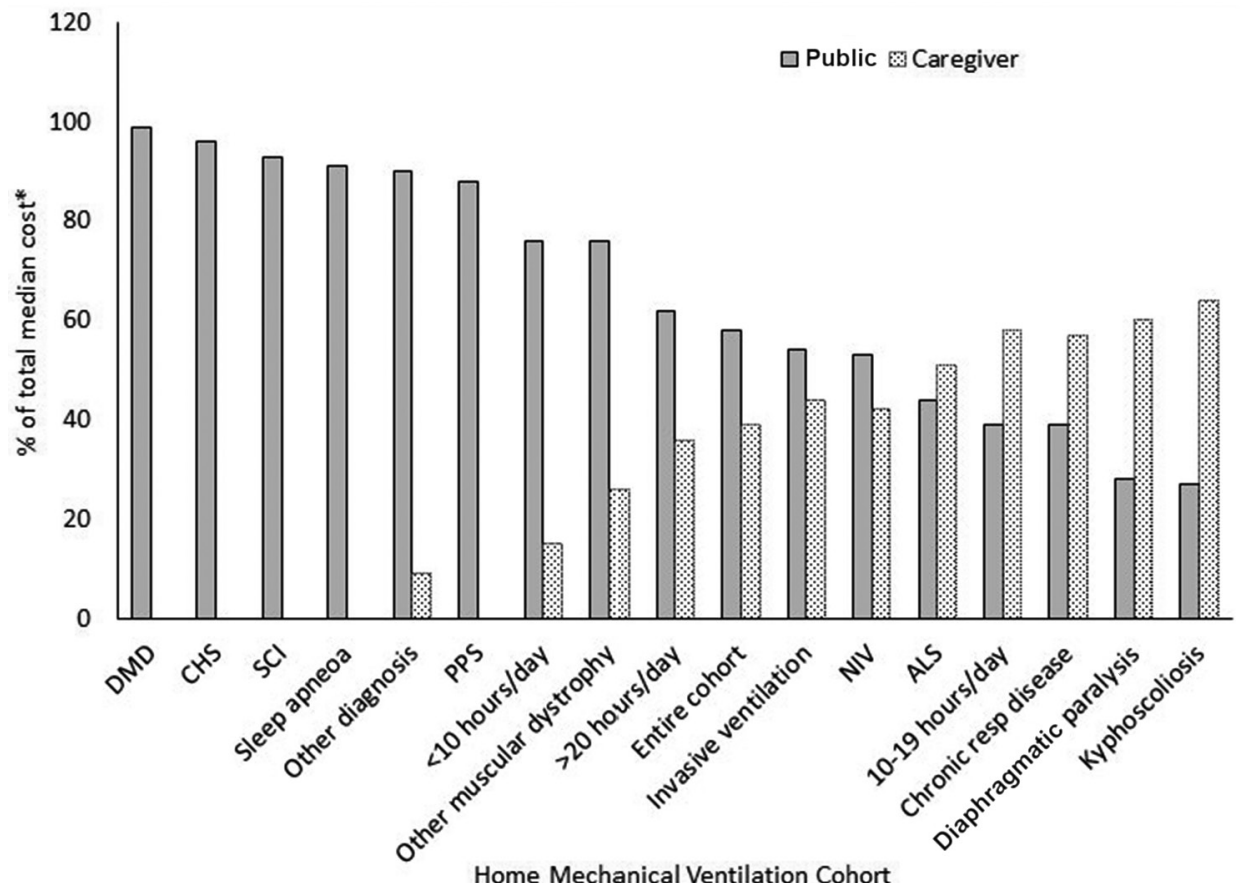

Figure 1 Graphical representation showing an inverse relationship in the proportion of public and caregiver lost time for most HMV user cohorts. *Because different cost categories did not sum to the total statistically derived median cost, the proportion of each category was calculated using the sum of median public+caregiver lost time+private out-of-pocket+third-party insurance as the denominator. ALS, amyotrophic lateral sclerosis; CHS, central hypoventilation syndrome; DMD, Duchenne muscular dystrophy; HMV, home mechanical ventilation; NIV, non-invasive ventilation; PPS, postpolio syndrome; resp, respiratory; $\mathrm{SCl}$, spinal cord injury.

deformities. ${ }^{3}$ Finally, our data are not generalisable to jurisdictions without publicly funded programmes for HMV users where there will be greater reliance on private health insurance and/or the family caregiver, with the possibility that these individuals may be unable to return home thus incurring greater public healthcare costs.

\section{CONCLUSION}

This study, which rigorously detailed publicly and privately funded monthly healthcare costs for HMV including time costs incurred

\begin{tabular}{|c|c|c|c|}
\hline Variable & $\begin{array}{l}\text { Exponentiated } \\
\text { estimate }\end{array}$ & $95 \% \mathrm{Cl}$ & $P$ value \\
\hline Intercept & & & $<0.0001$ \\
\hline $\begin{array}{l}\text { ALS diagnosis (ref=all other } \\
\text { diseases) }\end{array}$ & 1.88 & 1.09 to 3.26 & 0.03 \\
\hline \multicolumn{4}{|l|}{$\begin{array}{l}\text { FIM (ref=76th-100th } \\
\text { percentiles) }\end{array}$} \\
\hline 0th-25th percentiles & 6.98 & 3.88 to 12.55 & $<0.0001$ \\
\hline 26th-50th percentiles & 6.83 & 4.05 to 11.51 & $<0.0001$ \\
\hline 51st-75th percentiles & 2.93 & 1.91 to 4.50 & $<0.0001$ \\
\hline Male (ref=female) & 1.12 & 0.82 to 1.52 & 0.47 \\
\hline Age & 1.00 & 0.99 to 1.01 & 0.81 \\
\hline $\begin{array}{l}\text { Tracheostomy (ref=non- } \\
\text { invasive interfaces)+ }\end{array}$ & 1.41 & 0.89 to 2.25 & 0.15 \\
\hline Ventilation duration & 1.00 & 0.97 to 1.03 & 0.95 \\
\hline
\end{tabular}

We present exponentiated estimates as we log transformed 30-day healthcare costs. Adjusted $\mathrm{R}^{2}=55 \%$.

ALS, amyotrophic lateral sclerosis; FIM, Functional Independence Measure. by family caregivers, demonstrates substantial cost savings to the public healthcare system when these individuals live at home when compared with estimates of costs that occurred in acute or longterm care. Although public funding accounted for the highest proportion of costs, over one-third were due to caregiving time provided by family members. Healthcare costs were highest for those with the lowest functional independence and those with ALS. Our findings confirm the substantial public healthcare cost savings of facilitating mechanical ventilation in the home even when family caregiver time is properly costed, yet indicate that the burden to family caregivers is substantial and needs to be considered in future policy decisions related to HMV.

\section{Author affiliations}

${ }^{1}$ Faculty of Health Sciences, University of Ontario Institute of Technology, Oshawa, Ontario, Canada

${ }^{2}$ Department of Respiratory Therapy, Hospital for Sick Children, Toronto, Ontario, Canada ${ }^{3}$ Division of Respiratory Medicine, The Ottawa Hospital, Ottawa, Ontario, Canada

${ }^{4}$ Clinical Epidemiology Program, Ottawa Hospital Research Institute, Ottawa, Ontario, Canada

${ }^{5}$ Division of Respirology, Department of Medicine, Institute for Heart and Lung Health, University of British Columbia, Vancouver, British Columbia, Canada

${ }^{6}$ Institute of Health Policy, Management and Evaluation, University of Toronto, Toronto, Ontario, Canada

${ }^{7}$ Canadian Centre for Health Economics, Toronto, Ontario, Canada

${ }^{8}$ Lawrence S Bloomberg Faculty of Nursing, University of Toronto, Toronto, Ontario,

Canada

${ }^{9}$ Respiratory Medicine, West Park Healthcare Centre, Toronto, Ontario, Canada

${ }^{10}$ Department of Medicine, University of Toronto, Toronto, Ontario, Canada

${ }^{11}$ Division of Respirology, Department of Pediatrics, CHEO, University of Ottawa, Ottawa, Ontario, Canada

${ }^{12}$ Clinical Research Unit, CHEO Research Institute, Ottawa, Ontario, Canada

${ }^{13}$ Department of Critical Care Medicine, Sunnybrook Health Sciences Centre, Toronto, Ontario, Canada

Acknowledgements We acknowledge all the amazing individuals using home mechanical ventilation and their caregivers for taking the time to contribute to this 
study. In addition, we appreciate the help from administrative and clinical staff at each of our recruitment locations. We also acknowledge Regina Pizzuti, Carlie Brown, Gillian Harney and Lily Cheung for their vital contributions. Finally, thank you to the students who volunteered their time: Maleeha Kahn, Brittany Lindsay, Anna Reitano, Milad Anwari and Raymond Wong.

Contributors MLN and LR conceived the study concept and planned the study. MLN coordinated participant recruitment, collected data, and cleaned and managed the data. MW collected data. DG and PCC provided expertise regarding the Ambulatory and Home Care Record. BZ did cost calculations and data analysis. MLN and LR wrote the manuscript. All authors aided in participant recruitment, provided feedback and revisions, and approved the final manuscript.

Funding This work was funded by the Ontario Lung Association (Ontario Respiratory Care Society, Ontario Thoracic Society), Canadian Lung Association (Canadian Respiratory Health Professionals) and the ALS Society of British Columbia. MLN received a Canadian Thoracic Society Research Fellowship award during the conduct of this study. LR holds a Canadian Institutes of Health Research New Investigator award.

Competing interests None declared.

Ethics approval Research Ethics Boards of the University of Toronto, University of British Columbia, the Joint West Park-Toronto Central Community Care Access Centre-Toronto Grace Board, and Children's Hospital of Eastern Ontario.

Provenance and peer review Not commissioned; externally peer reviewed.

(c) Article author(s) (or their employer(s) unless otherwise stated in the text of the article) 2018. All rights reserved. No commercial use is permitted unless otherwise expressly granted.

\section{REFERENCES}

1 Lloyd-Owen SJ, Donaldson GC, Ambrosino N, et al. Patterns of home mechanical ventilation use in Europe: results from the Eurovent survey. Eur Respir $\mathrm{J}$ 2005;25:1025-31.

2 Laub M, Berg S, Midgren B; Swedish Society of Chest Medicine. Home mechanical ventilation in Sweden--inequalities within a homogenous health care system. Respir Med 2004;98:38-42.

3 Rose L, McKim DA, Katz SL, et al. Home mechanical ventilation in Canada: a nationa survey. Respir Care 2015;60:695-704.

4 Ontario Government Documents. Chronic ventilation strategy task force final report. Toronto, Canada: The Ministry of Health \& Long-term Care, 2006

5 MacIntyre EJ, Asadi L, Mckim DA, et al. Clinical outcomes associated with home mechanical ventilation: a systematic review. Can Respir J 2016;2016:1-10.

6 Liu JF, Lu MC, Fang TP, et al. Burden on caregivers of ventilator-dependent patients: a cross-sectional study. Medicine 2017;96:e7396.

7 Sevick MA, Bradham DD. Economic value of caregiver effort in maintaining long-term ventilator-assisted individuals at home. Heart Lung 1997;26:148-57.

8 Hung MC, Lu HM, Chen L, et al. Cost per QALY (quality-adjusted life year) and lifetime cost of prolonged mechanical ventilation in Taiwan. PLoS One 2012;7:e44043.

9 Indihar FJ. Cost comparison of care for chronic ventilator patients. Chest 1991;99:260.

10 LaFond L, Make B, Gilmartin M. Home care costs for ventilator-assisted individuals. Am Rev Respir Dis 1988;137:62.

11 Bach JR, Tran J, Durante S. Cost and physician effort analysis of invasive vs. noninvasive respiratory management of Duchenne muscular dystrophy. Am J Phys Med Rehabil 2015;94:474-82.

12 Bayliss M, Hamp C, Johnson D. College of respiratory therapists of ontario's optimizing respiratory therapy services: A continuum of care from hospital to community. Toronto: HealthForce Ontario - Optimizing Use of Health Providers' Competencies Fund 2008/09 Final Report, 2010

13 Health Canada. Health Care System: Canada's Health Care System. Secondary Health Care System: Canada's Health Care System. 2011. http://www.hc-sc.gc.ca/hcs-sss/ pubs/system-regime/2011-hcs-sss/index-eng.php (cited 11 Aug 2015).

14 Statistics Canada. Canadian Community Health Survey - Mental Health and WellBeing (CCHS). http://www23.statcan.gc.ca/imdb/p2SV.pl?Function=getSurvey\& SDDS=5015\&lang=en\&db=IMDB\&dbg=f\&adm=8\&dis=2 (accessed Nov 25 2016).

15 Finch E, Brooks D, Stratford PW, et al. (FIM $\left.{ }^{\top \mathrm{M}}\right)$ Functional independence measure. Physical rehabilitation outcome measures: a guide to enhanced clinical decision making. Hamilton: BC Decker Inc, 2002.
16 Guerriere DN, Coyte PC. The Ambulatory and Home Care Record: A Methodological Framework for Economic Analyses in End-of-Life Care. J Aging Res 2011;2011:1-11.

17 Leong VW, Guerriere DN, Croxford R, et al. The magnitude, share and determinants of private costs incurred by clients (and their caregivers) of in-home publicly financed care. Healthc Policy 2007;3:e141-59.

18 Yu M, Guerriere DN, Coyte PC. Societal costs of home and hospital end-of-life care for palliative care patients in Ontario, Canada. Health Soc Care Community 2015:23:605-18

19 McGillion MH, Croxford R, Watt-Watson J, et al. Cost of illness for chronic stable angina patients enrolled in a self-management education trial. Can J Cardiol 2008;24:759-64

20 Guerriere DN, Wong AY, Croxford R, et al. Costs and determinants of privately financed home-based health care in Ontario, Canada. Health Soc Care Community 2008;16:126-36.

21 Rice DP, Mackenzie EJ, et al. Cost of injury in the United States : a report to Congress, 1989. San Francisco; Baltimore: Institute for Health \& Aging, University of California, San Francisco; Injury Prevention Center, School of Hygiene and Public Health, the Johns Hopkins University, 1989

22 Torgerson DJ, Donaldson C, Reid DM. Private versus social opportunity cost of time: Valuing time in the demand for health care. Health Econ 1994;3:149-55.

23 Wilson Van Voorhis CR, Morgan BL. Understanding power and rules of thumb for determining sample sizes. Tutor Quant Methods Psychol 2007;3:43-50.

24 Andersen R, Newman JF. Societal and individual determinants of medical care utilization in the United States. Milbank Mem Fund Q Health Soc 1973;51:95-124.

25 Long-term Ventilation Strategy Advisory Group. Long-term Ventilation (LTV) Plan for the Care and Management of Individuals with LTV Needs: Ontario Ministry of Health \& Long-term Care. 2011.

26 Ministry of Finance Government of Ontario. News release. Providing a helping hand to those caring for loved ones. Ontario boosting respite support and training for family caregivers. Secondary news release. Providing a helping hand to those caring for loved ones. Ontario boosting respite support and training for family caregivers. 2017. https://news.ontario.ca/mof/en/2017/04/providing-a-helping-hand-to-those-caringfor-loved-ones.html

27 Sorrell JM. Moving Beyond Caregiver Burden: Identifying Helpful Interventions for Family Caregivers. J Psychosoc Nurs Ment Health Serv 2014;52:15-18.

28 Klein LM, Forshew DA. The economic impact of ALS. Neurology 1996;47:126S-9.

29 Luján M, Moreno A, Veigas C, et al. Non-invasive home mechanical ventilation: effectiveness and efficiency of an outpatient initiation protocol compared with the standard in-hospital model. Respir Med 2007;101:1177-82.

30 Hazenberg A, Kerstjens HAM, Prins SCL, et al. Initiation of home mechanical ventilation at home: $A$ randomised controlled trial of efficacy, feasibility and costs. Respir Med 2014;108:1387-95.

31 Gladman M, Zinman L. The economic impact of amyotrophic lateral sclerosis: a systematic review. Expert Rev Pharmacoecon Outcomes Res 2015;15:439-50.

32 Moss AH, Casey P, Stocking CB, et al. Home ventilation for amyotrophic lateral sclerosis patients: Outcomes, costs, and patient, family, and physician attitudes. Neurology 1993:43:438-43.

33 Landfeldt $E$, Lindgren $P$, Bell CF, et al. The burden of Duchenne muscular dystrophy: An international, cross-sectional study. Neurology 2014;83:529-36.

34 López-Bastida J, Perestelo-Pérez L, Montón-Álvarez F, et al. Social economic costs and health-related quality of life in patients with amyotrophic lateral sclerosis in Spain. Amyotrophic Lateral Sclerosis 2009;10:237-43.

35 Government of Canada. Family caregiver amount (FCA). Secondary Family caregiver amount (FCA). 2017. http://www.cra-arc.gc.ca/familycaregiver/

36 Government of Canada. Employment insurance compassionate care benefits. Secondary employment insurance compassionate care benefits. 2017. https:// www.canada.ca/en/employment-social-development/programs/ei/ei-list/reports/ compassionate-care.html

37 March of Dimes Canada. Home \& vehicle modification program. Secondary home \& vehicle modification program. 2017. http://www.marchofdimes.ca/EN/programs/ hvmp/Pages/HomeandVehicle.aspx

38 Canada Mortgage and Housing Corporation (CMHC). Accessible and Adaptable Housing. Secondary Accessible and Adaptable Housing. 2017. https://www.cmhc-schl. gc.ca/en/inpr/bude/index.cfm

39 Government of Ontario. Family caregiver leave. Secondary family caregiver leave. 2017. https://www.labour.gov.on.ca/english/es/pubs/guide/caregiver.php

40 Streiner D. Measurement. Health research methods, a canadian perspectives. Don Mills: Oxford University Press, 2014:119-42. 